\title{
The effect of octopaminergic compounds on the behaviour and transmission of Gyrodactylus
}

\author{
Adam J Brooker ${ }^{1 *}$, Mayra I Grano Maldonado', Stephen Irving², James E Bron', Matthew Longshaw ${ }^{2}$ and \\ Andrew P Shinn ${ }^{1}$
}

\begin{abstract}
Background: The high transmission potential of species belonging to the monogenean parasite genus Gyrodactylus, coupled with their high fecundity, allows them to rapidly colonise new hosts and to increase in number. One gyrodactylid, Gyrodactylus salaris Malmberg, 1957, has been responsible for devastation of Altantic salmon (Salmo salar L.) populations in a number of Norwegian rivers. Current methods of eradicating G. salaris from river systems centre around the use of non-specific biocides, such as rotenone and aluminium sulphate. Although transmission routes in gyrodactylids have been studied extensively, the behaviour of individual parasites has received little attention. Specimens of Gyrodactylus gasterostei Gläser, 1974 and G. arcuatus Bychowsky, 1933, were collected from the skin of their host, the three-spined stickleback (Gasterosteus aculeatus L.), and permitted to attach to the substrate. The movements of individual parasites were recorded and analysed.

Results: The behaviour patterns of the two species were similar and parasites were more active in red light and darkness than in white light. Four octopaminergic compounds were tested and all four inhibited the movements of parasites. Treatment ultimately led to death at low concentrations $(0.2 \mu \mathrm{M})$, although prolonged exposure was necessary in some instances.

Conclusions: Octopaminergic compounds may affect the parasite's ability to locate and remain on its host and these or related compounds might provide alternative or supplementary treatments for the control of $\mathrm{G}$. salaris infections. With more research there is potential for use of octopaminergic compounds, which have minimal effects on the host or its environment, as parasite-specific treatments against G. salaris infections.
\end{abstract}

Keywords: Gyrodactylus, octopamine, behaviour, toxicology

\section{Background}

As Gyrodactylus von Nordmann, 1832 (Monogenea) has no specific transmission stage in its life-cycle, movement between hosts must be achieved by strategies employed by the adult. Bakke et al. [1] suggested four routes by which gyrodactylids could transfer to a new host: (i) via contact with live hosts, (ii) via dead hosts, (iii) by detached parasites drifting in the water column, and (iv) by parasites attached to the substrate. This transmission potential, coupled with their high fecundity allows gyrodactylids to rapidly colonise new river systems $[1,2]$. Although transmission routes in gyrodactylids have been

\footnotetext{
* Correspondence: ajb3@stir.ac.uk

${ }^{1}$ Institute of Aquaculture, University of Stirling, Stirling FK9 4LA, UK

Full list of author information is available at the end of the article
}

studied extensively, few workers have investigated the behaviour of individual gyrodactylids.

Gyrodactylus salaris Malmberg, 1957 has devastated Atlantic salmon (Salmo salar L.) populations where it is present in North European rivers [3] and currently the only method of eradicating G. salaris from river systems is by using biocides, such as rotenone. However, this is devastating for the river habitat and, once it has recovered, G. salaris can re-colonise the river if measures are not taken to prevent its re-introduction [2]. Consequently, the focus of research is moving towards finding alternative methods to control G. salaris, which target the pathogen without seriously affecting the river ecosystem. This requires an increased understanding of gyrodactylid biology and behaviour [4].
C Biomed Central

C 2011 Brooker et al; licensee BioMed Central Ltd. This is an Open Access article distributed under the terms of the Creative Commons Attribution License (http://creativecommons.org/licenses/by/2.0), which permits unrestricted use, distribution, and reproduction in any medium, provided the original work is properly cited. 
In the control of other pathogens, chemical treatments often target specific stages of the life-cycle, which can be exploited to reduce the survival or infectivity of the parasites e.g. teflubenzuron is used to disrupt the moult of sea lice (Lepeophtheirus salmonis Krøyer, 1837 and Caligus elongatus Nordmann, 1832) [5]. Neurotransmitter receptor agonists/antagonists are compounds that elicit a response by binding to a postsynaptic receptor (e.g. on muscle or nerve) and mimicking or blocking the natural transmitter. In this study, the effect of octopaminergic receptor agonists/antagonists on gyrodactylids was investigated. It is suggested that exposing gyrodactylids to these compounds may affect their ability to attach to a host, rendering them immobile and unable to infect a host.

In order to investigate the effect of octopaminergic chemicals on the behaviour of gyrodactylids, it was necessary to develop a bioassay to observe their behaviour. Therefore, the objectives of the study were to: 1) develop a system for recording and observing the movements of gyrodactylids under different lighting conditions; 2) determine optimum lighting conditions for observing the behaviour of gyrodactylids, by comparing their movements under white light, red light and in dark conditions; and 3) determine the efficacy of the four octopaminergic compounds on detached gyrodactylid behaviour.

\section{Materials and methods}

\section{Source of parasites}

As Gyrodactylus salaris is a notifiable pathogen in the UK, it was not possible to acquire them for use in this study and therefore gyrodactylids from three-spined sticklebacks (Gasterosteus aculeatus L.), which are easily obtainable, were used as a gyrodactylid model. Two species of Gyrodactylus were identified from sticklebacks, G. gasterostei Gläser, 1974 and G. arcuatus Bychowsky, 1933 , although the former were in the majority $(80 \%$ and $20 \%$, respectively). Both species were used in the behaviour experiments.

Three-spined sticklebacks were netted from a tributary of the River Forth, Stirlingshire (56 $06^{\circ} 37.77^{\prime \prime} \mathrm{N}, 3^{\circ} 58^{\prime}$ $\left.25.25^{\prime \prime} \mathrm{W}\right)$ and maintained at $10^{\circ} \mathrm{C}$ in 30 litre, static tanks in an aquarium facility at the Institute of Aquaculture, University of Stirling. A 50\% water change was carried out daily, using water collected from Loch Airthrey (56 $08^{\circ} 39.53^{\prime \prime} \mathrm{N}, 3^{\circ} 53^{\prime} 51.20^{\prime \prime} \mathrm{W}$ ) and the sticklebacks were fed ad libitum with frozen bloodworm (Gamma, Chorleywood, UK). Gyrodactylus for use in the behaviour experiments were removed from the sticklebacks using triangular mounted surgical needles (size 16, Barber of Sheffield, UK). Parasites were identified to species level using standard descriptions. Once the behaviour of each gyrodactylid had been determined, it was fixed and mounted in ammonium picrate glycerine according to the method detailed by Malmberg [6], identified and its maturity status determined (i.e. presence or absence of a male copulatory organ and/or an embryo in utero).

\section{Investigation of lighting conditions}

Initially, a simple experiment was undertaken to determine the activity of gyrodactylids under light and dark conditions. A mark was made on the underside of a $9 \mathrm{~cm}$ diameter Petri dish using a permanent marker and a single Gyrodactylus was placed onto the mark in the Petri dish filled with stream water at $10^{\circ} \mathrm{C}$. Parasites attached themselves by the haptor and twenty replicates of each were maintained in either ambient light (2800 lux) or dark conditions (0 lux). The replicates in ambient light were placed inside a cotton light-diffusing box to scatter the light and eliminate any directional cues. After three hours the straight line distance between the final position of the Gyrodactylus and the initial mark was measured.

\section{Gyrodactylus tracking}

An experimental system was constructed to record the behaviour of individual Gyrodactylus (Figure 1). This consisted of a $110 \mathrm{~mm}$ section of PVC pipe with a divider inserted inside the pipe. A circular hole $52 \mathrm{~mm}$ in diameter was cut in the divider and a mirror was placed underneath the divider at an angle of $45^{\circ}$. A $5 \mathrm{~cm}$ diameter Petri dish with a painted matt black base was placed onto supports surrounding the circular hole. Light was provided by a Carousel S $150 \mathrm{~W}$ slide projector, which was directed onto the mirror, deflecting the light up through the divider and around the Petri dish. A foil

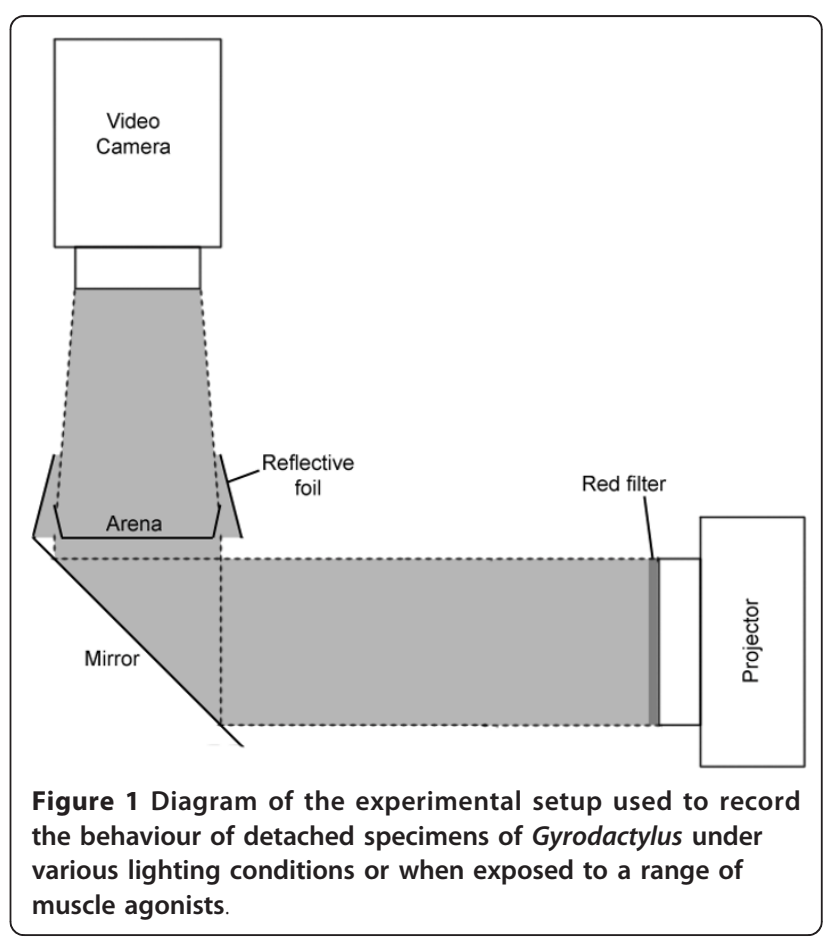


cone set at an angle of $\sim 30^{\circ}$ directed light back into the centre of the Petri dish, forming a ring of incident light. This allowed the gyrodactylid to be detected in the arena and eliminated any directional light cue as the light level was consistent around the whole dish (Figure 1). A Canon MiniDV MD205 video camera was mounted on a stand above the arena to record the movements of the Gyrodactylus. Inflated circular rubber inner tubes measuring 20 and $50 \mathrm{~cm}$ in diameter were placed underneath the projector and the tray containing the light chamber to dampen vibrations from the projector.

For each replicate a new $5 \mathrm{~cm}$ diameter painted Petri dish was filled with $10 \mathrm{ml}$ of $0.2 \mu \mathrm{m}$ filtered stream water at $10^{\circ} \mathrm{C}$ and a single Gyrodactylus was placed into the centre of the arena using a Gilson pipette. It was then placed into the light chamber and left to settle for 20 minutes. The subsequent behaviour of the parasite was then recorded ( $\mathrm{T}_{20-50}$ mins) onto MiniDV cassettes, using the video camera, for 30 minutes, before being fixed and mounted onto a glass slide. Ten replicates were recorded in white light ( 2800 lux) and ten in red light, using a Hoya $600 \mathrm{~nm}(590-2750 \mathrm{~nm})$ red photographic filter placed over the projector lens.

The 30 minute videos were converted to digital video files in.avi format using Windows Moviemaker software (version 2.1.4028.0, Microsoft Corporation, 2007). Individual frames in bitmap format were extracted using Bink and Smacker software (Bink version 1.9L, Smacker version 4.2d, RAD Game Tools Inc., 2009) at a frame rate of 1 frame per 5 seconds. Shade correction and segment analysis of the image set was performed in KS300 software (version 3.0 Carl Zeiss Vision GmbH, 1997) to facilitate the tracking of the parasite. Paratrack software (version 2.4, A. Brooker, University of Stirling, 2007) was used to track the movements of the parasite in each frame, creating an image of the gyrodactylid's movements and a text file containing a list of co-ordinates of the parasite's location in each frame. Once the parasites had been tracked the lists of co-ordinates were time averaged over three steps ( 15 seconds) to smooth the data, removing any bias in the calculated behaviour parameters as a result of exploratory extensions by the gyrodactylids whilst their haptors are stationary. The resultant co-ordinates were then used to calculate behavioural information including the mean and maximum velocity of each parasite, the distance travelled, turn rate, meander and heading. Fractal dimensions, which are a measure of track complexity, were also calculated for the parasite tracks using the 'box counting' method $[7,8]$. These operations were all undertaken using the Paratrack software. Principal Component Analysis (PCA -Statistica 6.1 software, 2004, Statsoft Inc., USA) was used to investigate differences between gyrodactylid movements in white and red light.

\section{Chemical efficacy}

The following four octopaminergic compounds were tested in this trial: $( \pm)$-octopamine hydrochloride $\left(\mathrm{C}_{8} \mathrm{H}_{11} \mathrm{NO}_{2}\right.$. $\mathrm{ClH}$; O0250 Sigma), clonidine hydrochloride $\left(\mathrm{C}_{9} \mathrm{H}_{9} \mathrm{Cl}_{2} \mathrm{~N}_{3} . \mathrm{ClH}\right.$; C7897 Sigma), amitraz (N-methylbis(2,4-xylyl iminomethyl) amine, $\mathrm{C}_{19} \mathrm{H}_{23} \mathrm{~N}_{3}$; 45323 Riedel-de Haën/Sigma) and chlordimeform $\left(\mathrm{C}_{10} \mathrm{H}_{13} \mathrm{ClN}_{2}\right.$; 35913 Riedel-de Haën/Sigma). Chlordimeform was selected as a positive reference as it is known to be effective in the control of invertebrates and is toxic to aquatic life [9]. Octopamine is a biogenic monoamine found predominantly in invertebrates and modulates physiological activity by binding to adrenoceptors. In invertebrates it acts as a neurohormone, a neuromodulator or a neurotransmitter and modulates almost every physiological process [10]. In vertebrates noradrenaline is homologous to octopamine in invertebrates. Octopamine is found at concentrations less than $1 \%$ of noradrenaline in vertebrates, with its physiological activity being only $1-2 \%$ of noradrenaline [11]. Clonidine is a centrally-acting $\alpha$-adrenergic receptor agonist and is known to reduce involuntary muscle contractions, or tics, in humans by binding to $\alpha 2$-adrenergic receptors [12]. Its mode of action is inhibition of adrenergic receptors, which results in reduced motor activity [13]. Amitraz and chlordimeform belong to a group of insecticides/acaricides (formamidines) whose mode of action is by interaction with octopamine receptors [13]. They work by mimicking the action of octopamine (centrally and at the neuromuscular junction) in invertebrates [14]. Amitraz acts as a receptor agonist, whereas chlordimeform has an antagonistic effect $[15,13]$. Although certain groups of invertebrates have been shown to be particularly sensitive to formamidine compounds (Acarines, Lepidoptera and Hemiptera), vertebrates in general are relatively insensitive [16]. Both chemicals have anthelmintic properties [17] and have been shown to induce hyperexcitation and detachment of feeding ticks $[18,19]$.

As the efficacy of the four octopaminergic compounds on Gyrodactylus was unknown, a simple dose ranging exposure experiment was carried out using serial dilutions of each chemical with distilled water prepared in concentrations of $32,16,8,4$ and $2 \mu \mathrm{M}$ plus a control consisting of distilled water only. One $\mathrm{ml}$ of each of these dilutions was pipetted into $5 \mathrm{~cm}$ diameter Petri dishes containing $9 \mathrm{ml}$ of filtered stream water at $10^{\circ} \mathrm{C}$ to give final concentrations of 3.2, 1.6, 0.8, 0.4 and $0.2 \mu \mathrm{M}$. A single Gyrodactylus specimen was introduced into each Petri dish, which were then kept in an incubator at $10^{\circ} \mathrm{C}$. Each chemical concentration was replicated 15 times. The parasites were checked after 24 and $48 \mathrm{~h}$ and recorded as alive, affected (i.e. not attached and showing muscular spasms), moribund (i.e. not attached, curled up and showing minute muscular contractions) or dead (i.e. no response to physical stimulus). After $48 \mathrm{~h}$ the gyrodactylids were preserved 
in ethanol for future identification and maturity assessment. After applying Abbot's correction factor [20] to account for control mortality, probit analysis (Minitab 13.1 Software, 2000, Minitab Inc., USA) was used to calculate $24 \mathrm{~h}$ and $48 \mathrm{~h} 50 \%$ effective concentration (EC50) values for each of the octopaminergic compounds. Where EC50 values are given, figures in parentheses are fiducial limits.

\section{Results}

\section{Lighting conditions}

As there was no significant difference between the distances travelled by each species of Gyrodactylus the data were combined. The investigation suggested that Gyrodactylus are more active in dark than in light conditions $(\mathrm{P}=$ $<0.001$, one-way ANOVA) (Figure 2). After three hours, parasites in dark conditions moved a mean distance of $28.37 \pm 10.18 \mathrm{~mm}$ from their starting point, whereas those in white light conditions moved only $11.8 \pm 10.13 \mathrm{~mm}$.

\section{Tracking}

Observation of the 30 minute tracks of individual Gyrodactylus showed several different behaviour patterns that were common to both species of Gyrodactylus tested: The most common behaviour involved moving in one direction with little deviation from the chosen heading (Figure 3a); the movements of some individuals were confined to a very small area around the starting point

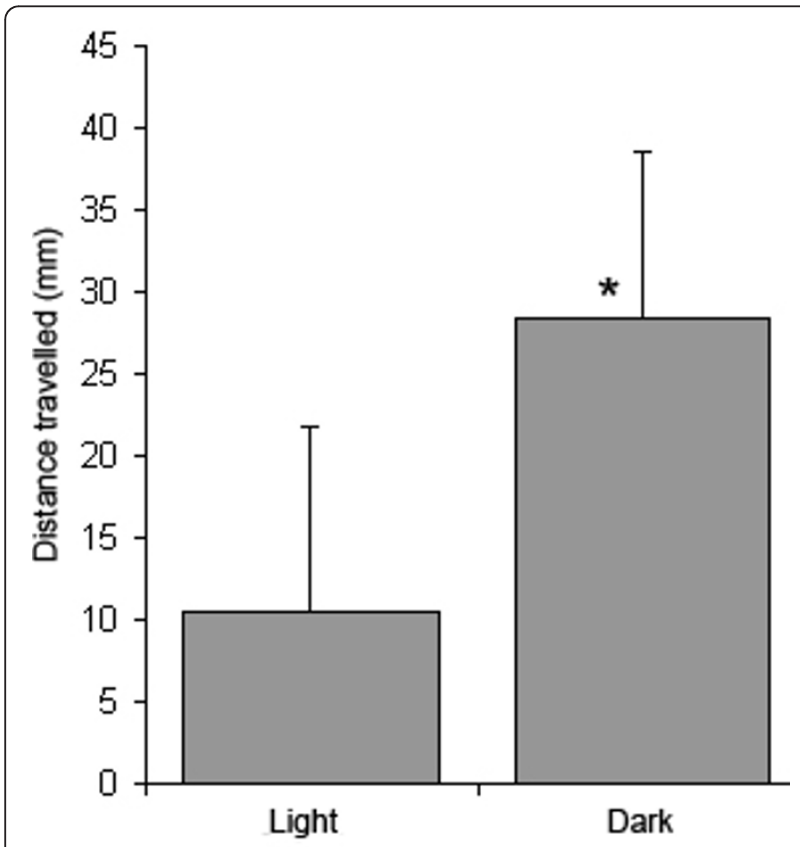

Figure 2 Distance travelled by Gyrodactylus after $3 \mathrm{~h}$ in light ( $=19)$ and dark $(n=19)$ conditions. Bars $=1$ S.D., ${ }^{*}=$ significant difference from white light response $(p<0.001)$.

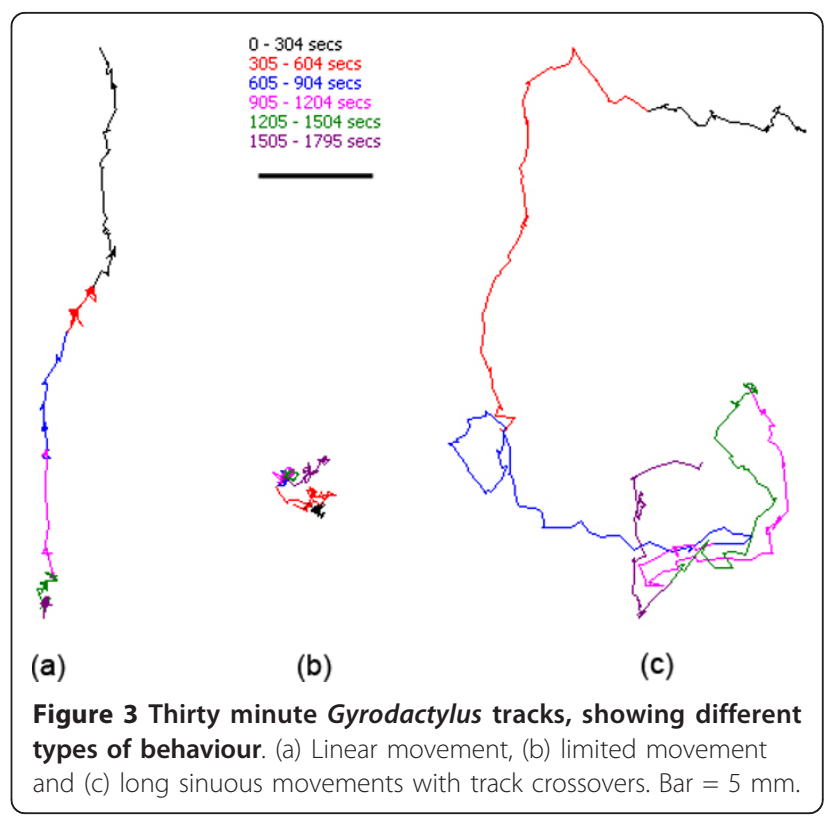

(Figure 3b); the final behaviour pattern can be described as extensive sinuous movements, with several path crossovers (Figure 3c). Individuals recorded in white light conditions appeared to display the first and second behaviour patterns, whereas individuals recorded under red light appeared to have longer, more sinuous tracks. No correlation was found between the different behaviour types and the species or maturity status of the individual gyrodactylids.

Analysis of the tracks revealed that gyrodactylids in red light $(\mathrm{n}=10)$ had a higher mean velocity $(0.18 \pm$ $0.17 \mathrm{~mm} / \mathrm{sec})$ and maximum velocity $(0.78 \pm 0.35 \mathrm{~mm} /$ sec), travelled further $(6.32 \pm 5.81 \mathrm{~cm})$ and had a higher turn rate $( \pm 26.6$ degrees/sec) compared to those in white light $(\mathrm{n}=10)$, which had a mean velocity of $0.11 \pm$ $0.10 \mathrm{~mm} / \mathrm{sec}$, maximum velocity of $0.51 \pm 0.28 \mathrm{~mm} / \mathrm{sec}$, travelling distance of $4.04 \pm 3.35 \mathrm{~cm}$ and turn rate of $20.35 \pm 6.79$ degrees/sec (Figure 4). However, none of these values were significantly different (one-way ANOVA). Fractal dimensions and meander were lower for gyrodactylids in red light $(0.69 \pm 0.2$ and $856 \pm 397$ degrees $/ \mathrm{mm})$ than for those in white light $(0.85 \pm 0.2$ and $1195 \pm 373$ degrees $/ \mathrm{mm}$ ), indicating less complex tracks for those in red light, although again none of these values were significantly different (one-way ANOVA). The behavioural data was analysed (one-way ANOVA) for differences according to species of Gyrodactylus and maturity status, but none were found and no patterns in the data were apparent, suggesting that the different behaviours observed in this study are unrelated to the species and/or age of the gyrodactylids.

The behaviour data was subjected to Principal Component Analysis (PCA) to reveal differences between 

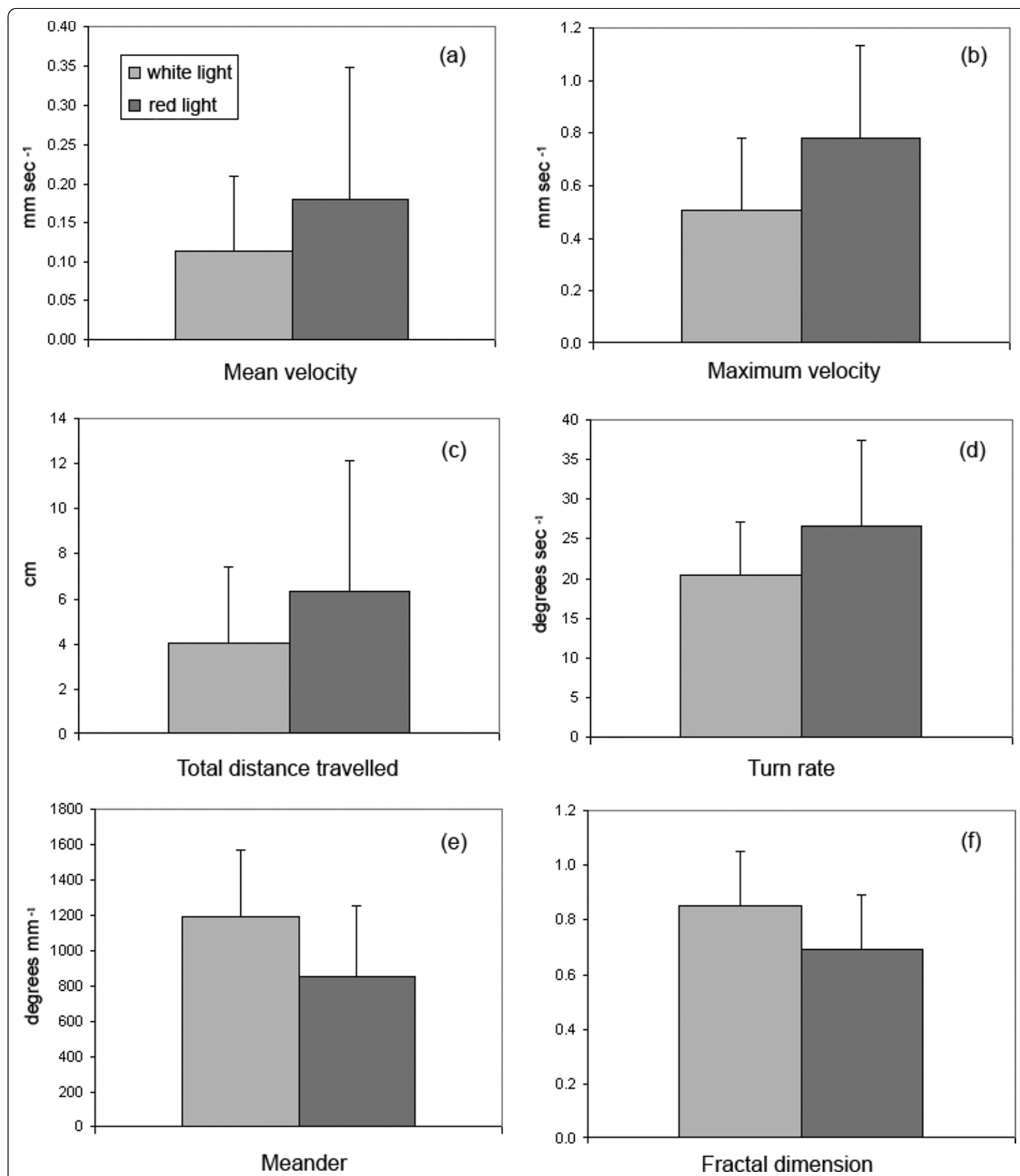

Figure 4 Behaviour parameters for Gyrodactylus recorded in white and red light conditions $(\mathbf{n}=\mathbf{1 0})$. (a) mean velocity; (b) maximum velocity; (c) distance travelled; (c) turn rate; (e) meander and ( $f$ ) fractal dimension. Bars = 1 S.D.

gyrodactylid behaviour in white light and red light. The behaviour parameters that showed the greatest differences between white light and red light (one-way ANOVA) were chosen (i.e. maximum velocity, meander and fractal dimension) and checked for normality (the remaining parameters were found to be too variable to show any patterns in behaviour). The maximum velocity data was found to be skewed, so was log transformed to 
normalise it. Eigen values for Factors 1 and 2 were $66.3 \%$ and $25.8 \%$, respectively, describing a total of $92.1 \%$ of the variation in the data. The PCA plot shows two distinct groups according to behaviour in white light and red light, although some individuals in white light were grouped with those in red light (Figure 5). Examination of the individual tracks confirmed that those individuals in white light that were grouped with those in red light exhibited behaviour typical of those in red light (i.e. long, sinuous tracks).

\section{Chemical efficacy}

All of the four compounds affected Gyrodactylus and produced involuntary muscular contractions (spasms) when normal body extension was attempted. A mortality of $10 \%$ was seen in the control group after 48 hours, although no muscle spasms were observed. As the positive reference, the highest concentration of $3.2 \mu \mathrm{M}$ of chlordimeform affected $87 \%$ of gyrodactylids after $24 \mathrm{~h}$ as denoted by limited movements (Figure 6a). However, after 48 h 27\% of gyrodactylids were unaffected (Figure 6b) suggesting that (i) the muscular spasms may only be temporary at that concentration; (ii) the gyrodactylids needed to be at a particular physiological state before they became susceptible; (iii) the persistence of the compound affects its efficacy. As there was no clear trend in the numbers of dead, moribund and affected gyrodactylids (Figure 6a, b), it was not possible to accurately calculate EC50 values for chlordimeform.

Octopamine had a dose dependent response after $24 \mathrm{~h}$, with $73 \%$ of gyrodactylids being either affected, moribund or dead at the highest concentration of $3.2 \mu \mathrm{M}$, compared to $27 \%$ at the lowest concentration of $0.2 \mu \mathrm{M}(\mathrm{EC} 50=$ $0.89 \mu \mathrm{M}(0.46-1.94 \mu \mathrm{M})$ ) (Figure $6 \mathrm{c})$. After $48 \mathrm{~h}$ the majority $(67 \%)$ of the gyrodactylids were dead at $3.2 \mu \mathrm{M}$ (Figure $6 d)$. Numbers of affected and moribund gyrodactylids

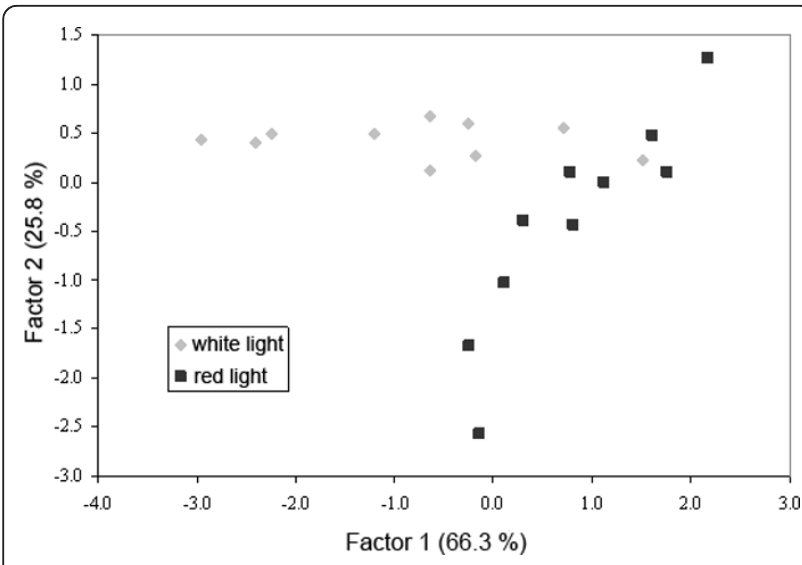

Figure 5 Principal Component Analysis of maximum velocity, meander and fractal dimension for gyrodactylids exposed to white light $(n=10)$ and red light $(n=10)$. were low for all concentrations (7\%-27\%) after 48 h suggesting that the optimum exposure time for octopamine is between 24 and $48 \mathrm{~h}$. The $48 \mathrm{~h}$ EC50 for octopamine was $0.25 \mu \mathrm{M}(0-0.54 \mu \mathrm{M})$.

Clonidine was effective after $24 \mathrm{~h}$ with $60 \%$ of gyrodactylids being either affected, moribund or dead at both $3.2 \mu \mathrm{M}$ and $0.2 \mu \mathrm{M}$ (Figure $6 \mathrm{e}$ ). After $48 \mathrm{~h}$ this figure had increased to $87 \%$ at $3.2 \mu \mathrm{M}$ and $80 \%$ at $0.2 \mu \mathrm{M}$ (Figure 6f). As there was little difference in the number of affected gyrodactylids between the highest and lowest doses, it is possible that either the concentration range selected was too narrow to determine the effective range or there are other factors affecting the efficacy of the compound. Therefore, it was not possible to accurately calculate EC50 values for clonidine. However, as the number of affected and moribund gyrodactylids was low after $48 \mathrm{~h}$ (7\%-27\%), it is suggested that, similar to octopamine, the optimum exposure time for clonidine is between 24 and $48 \mathrm{~h}$.

Amitraz was the most effective of the compounds tested with $100 \%$ of gyrodactylids being either affected, moribund or dead after $24 \mathrm{~h}$ at the highest concentration of $3.2 \mu \mathrm{M}$ (53\% dead) (Figure $6 \mathrm{~g}$ ). At $0.2 \mu \mathrm{M} 66 \%$ remained unaffected with $20 \%$ being either affected or moribund. The $24 \mathrm{~h}$ EC50 for amitraz was $0.31 \mu \mathrm{M}$ (0.18-0.44 $\mu \mathrm{M})$. After $48 \mathrm{~h} 60 \%$ were dead at $3.2 \mu \mathrm{M}$ and $27 \%$ were dead at $0.2 \mu \mathrm{M}$ (Figure $6 \mathrm{~h}$ ). As there were a considerable number of gyrodactylids either affected or moribund after $48 \mathrm{~h}$ (33-47\%), and the numbers either affected, moribund or dead after $48 \mathrm{~h}$ were similar to those after $24 \mathrm{~h}$, it is likely that the optimum exposure time for amitraz is longer than $48 \mathrm{~h}$. The $48 \mathrm{~h}$ EC50 value for amitraz was $0.18 \mu \mathrm{M}(0.05-0.27 \mu \mathrm{M})$.

\section{Discussion}

These results suggest that gyrodactylids are more active in the dark than in light and therefore imply that they possess some form of photoreceptor. Watson and Rohde [21] found sensory receptors in Gyrodactylus sp., which closely resemble photoreceptors found in other platyhelminths [22,23]. The light/dark experiment shows a significant difference in the distance travelled between those gyrodactylids in the dark and those exposed to light. However, as this experiment only records the start and end position of the parasite, the trial assumes that parasites have travelled in a straight line and, therefore, it is impossible to quantify their movements during the period of the experiment i.e. whether they follow a straight or sinuous path. This does, however, suggest that there may be differences in the distance travelled by gyrodactylids under different lighting conditions.

Although parasite tracks cannot be determined in the "dark", they can be measured under red and infrared light. By recording and tracking all the movements of 

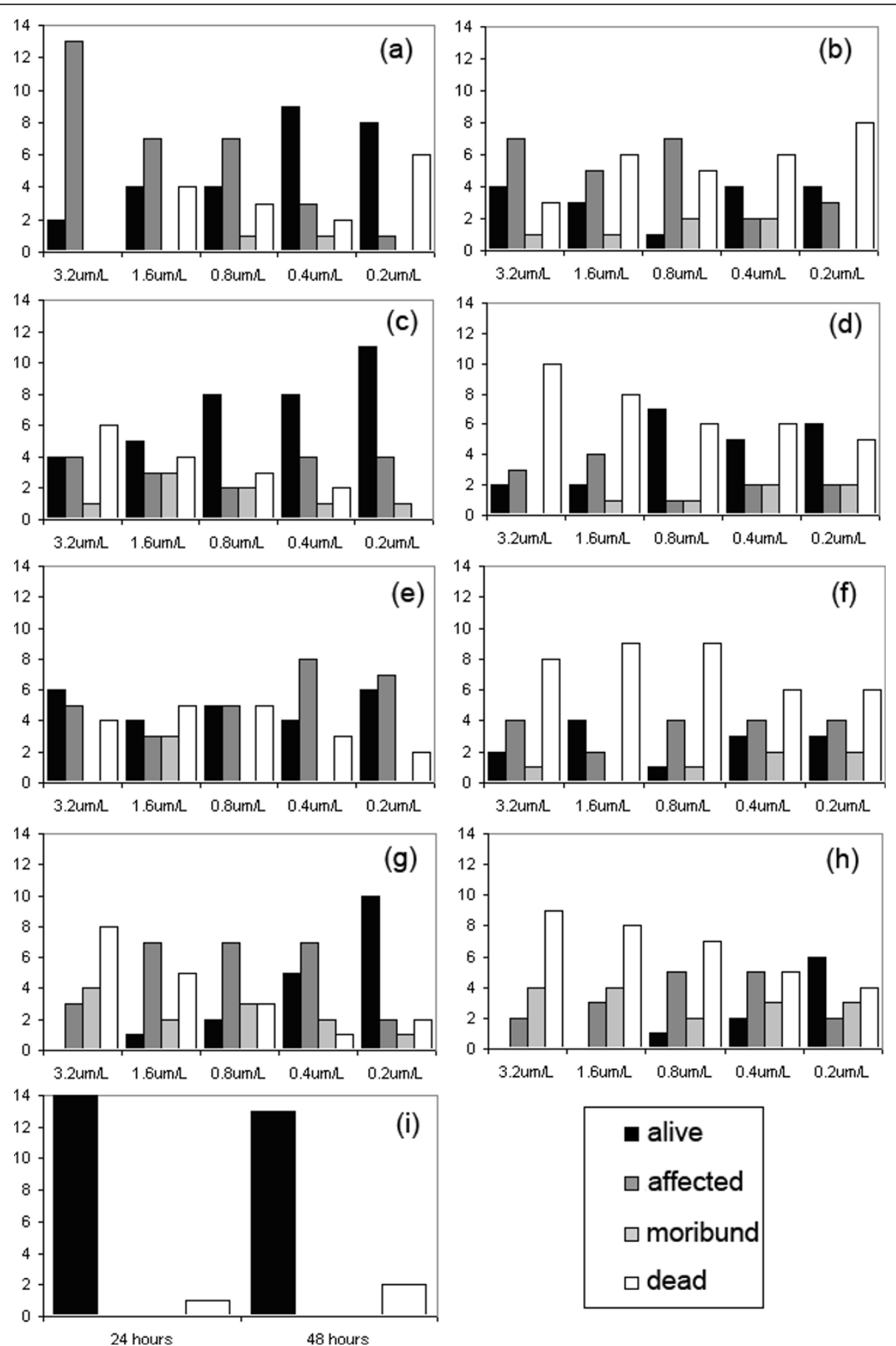

Figure 6 Effect on Gyrodactylus of (a) chlordimeform after 24 h, (b) chlordimeform after 48 h, (c) octopamine after 24 h, (d) octopamine after 48 h, (e) clonidine after 24 h, (f) clonidine after 48 h, (g) amitraz after 24 h, (h) amitraz after 48 h and (i) control. (y axes $=$ number of individual gyrodactylids, $\mathrm{n}=15$ for each compound tested).

individual Gyrodactylus it is possible to quantify their movements. While most of the measured movement parameters (velocity, distance travelled, turn rate) were higher for those gyrodactylids in red light than those in white light, none of the differences were significant. This is an indication of the wide variation in behaviours, resulting in large deviations from the mean. Conversely, meander and fractal dimensions were lower for gyrodactylids in red light than those in white light, indicating less complex tracks than those in white light. By using the 
movement parameters showing the greatest differences between white and red light it was possible to discriminate between the two lighting conditions using PCA. This suggests that the different conditions do result in different behaviours, although more replicates would be required to state categorically whether there are significant differences in their movements.

Observations of the tracks showed that gyrodactylids in white light often had unidirectional tracks, whereas those in red light were generally more sinuous. However, in several individuals the converse was true. Therefore, it appears that exposure to a specific cue (e.g. red or white light) does not always elicit a behavioural response typical of the majority of individuals exposed to the cue.

The difference in behaviour in red and white light may relate to their natural behaviour in situ. The long sinuous tracks of the gyrodactylids in red light, which had lower complexity and meander than those in white light, may indicate a host-seeking behaviour. Covering a large surface area as quickly as possible may allow them to identify chemical or physical cues used in host location. For example, ciliary structures likely to be photoreceptors found in Gyrodactylus sp. [21] may be involved in a shadow response [24], allowing gyrodactylids to detect a potential host moving overhead whilst attached to the substrate. In comparison, the behaviour exhibited by the gyrodactylids in white light (uni-directional tracks or limited movements) may indicate a response to either seek shade or conserve energy in anticipation of darkness. This implies that host-seeking behaviour is more likely to occur in dull or dark conditions. Host transmission may be more favourable at night depending on host behaviour e.g. if hosts are less active at night and aggregate with other hosts. Transmission during darkness may also minimise the chances of being eaten by hosts that forage during the day.

Orientation with respect to directional light requires photoreceptors with pigment shields. Although structures assumed to be light receptors have been found in gyrodactylids [21] they have no associated pigment shields. Therefore, it is likely that directional choices made by individual gyrodactylids are random and not related to directional light cues.

Host transmission may be associated with particular maturity stages of individual gyrodactylids, e.g. when newborn or after giving birth. However, no correlation was found between the behaviour patterns of individual Gyrodactylus and their maturity status. Although this does not necessarily indicate that maturity status is not linked to tranmission, (as the gyrodactylids had already been physically removed from their hosts) it does suggest that light may provide a stronger behavioural cue than maturity status, once they are detached.
The distances travelled by gyrodactylids in this study give an indication of the transmission potential via the substrate. In the tracking experiment, gyrodactylids in red light travelled a mean distance of $6.32 \mathrm{~cm}$, which equates to $3.03 \mathrm{~m}$ over a $24 \mathrm{~h}$ period and in white light travelled a mean distance of $4.04 \mathrm{~cm}$, equating to $1.94 \mathrm{~m}$ over $24 \mathrm{~h}$. Transmission rates are temperature dependent and activity may increase at higher temperatures [25], indicating the dispersal and transmission potential via the substrate for detached gyrodactylids. Comparing the distances travelled in the tracking experiment with those in the experiment investigating lighting conditions, gyrodactylids travelled significantly further in the dark than in white light, suggesting that distances travelled by gyrodactylids in the dark may be even greater.

Of the four octopaminergic compounds tested, all had an effect on gyrodactylids. The initial effect was to induce muscular spasms as the parasites attempted to extend their bodies. Prolonged exposure resulted in death. It is not known if this response reflects an interaction at the peripheral or central nervous system, but does imply the presence of octopaminergic receptors. Although chlordimeform severely affected the parasites, amitraz had an even stronger effect, even at low concentrations down to $0.2 \mu \mathrm{M}$. Only chlordimeform at higher concentrations and amitraz significantly affected the parasites after $24 \mathrm{~h}$. With octopamine and clonidine the full effect was not seen until after $48 \mathrm{~h}$. This has implications for use of this type of treatment in the field, as prolonged exposure $(24+\mathrm{h})$ may be required to have any significant effect on gyrodactylids, although this delay between application and effect may be shortened with another compound due to pharmacokinetic considerations. As octopamine is a natural biogenic amine, it will be subject to metabolism and uptake by the gyrodactylids so its effect will be affected by physiological processes. This may also be the case for clonidine. As chlordimeform and amitraz are synthetic compounds, they are less likely to be affected by uptake and metabolism. In addition, it should be noted that the bioassay used in this study is relatively crude. The complex behaviours of sensory host detection followed by co-ordinated tactic motor activity involve considerable complexity and it is probable that the small behavioural effects found at very low concentrations can confer considerable efficacy for control in the field.

As the survival rates of gyrodactylids off the host are 1 day at $18^{\circ} \mathrm{C}$ and 4 days at $3^{\circ} \mathrm{C}$ for G. salaris [4] and 2.7 days at $15^{\circ} \mathrm{C}$ and 4.2 days at $4^{\circ} \mathrm{C}$ for G. gasterostei [26], this type of experiment is prone to error as a result of natural mortalities. Although mortalities in the control were only $10 \%$ it is important to bear in mind the survival rates off the host when interpreting the results. To account for 
control mortality an appropriate correction factor must be used, such as Abbots or Schneider-Orelli.

Before any chemical treatment against G. salaris can be used for entire river habitats, the toxicity of the compound to human operators and to other flora and fauna must be established. An ideal effective treatment should affect the target organism, without having adverse effects on other aquatic life. However, as the desired mode of action of any octopaminergic treatment is to interfere with the subtle behaviour of gyrodactylids, the concentrations of compound required will be considerably lower than those required to kill the parasites. As octopamine modulates virtually all physiological processes in invertebrates, but shows very little activity in vertebrates, being homologous to noradrenaline in vertebrates [7], it is likely that it will have minimal effects on vertebrates at the concentrations required to disrupt physiological processes in invertebrates. No information is available on the toxicity of octopamine in fish, although results have shown that it is non-toxic to mammals [27]. However, it is likely that the toxicity of octopamine in other aquatic invertebrates is similar to that of gyrodactylids. Although it was not possible to calculate EC50 values for chlordimeform in this study, $73 \%$ of gyrodactylids were affected or dead after $48 \mathrm{~h}$ at the lowest concentration of $0.2 \mu \mathrm{M}(0.04 \mathrm{mg} / \mathrm{L})$, which is considerably lower than the $96 \mathrm{~h}$ LC50 for rainbow trout (Oncorhynchus mykiss Walbaum) at $13.2 \mathrm{mg} / \mathrm{L}$ [6]. Similarly, it was not possible to calculate EC50 values for clonidine. However, at $0.8 \mu \mathrm{M}(0.21 \mathrm{mg} / \mathrm{L}) 93 \%$ of gyrodactylids were affected or dead after $48 \mathrm{~h}$. Considering that the $96 \mathrm{~h} \mathrm{LC50}$ for clonidine in ide (Leuciscus idus (L.)) is $87 \mathrm{mg} / \mathrm{L} \mathrm{[28],} \mathrm{it} \mathrm{is} \mathrm{likely} \mathrm{that} \mathrm{the} \mathrm{EC50} \mathrm{in}$ gyrodactylids is significantly lower. In addition, $80 \%$ of gyrodactylids were affected by clonidine after $48 \mathrm{~h}$ at 0.2 $\mu \mathrm{M}(0.053 \mathrm{mg} / \mathrm{L})$, which is a concentration significantly lower than the $48 \mathrm{~h}$ EC50 for Daphnia of $182 \mathrm{mg} / \mathrm{L}$ [28]. Amitraz has a $24 \mathrm{~h}$ EC50 of $0.29 \mu \mathrm{M}(8.5 \mathrm{mg} / \mathrm{L})$ for gyrodactylids, which is higher than the $24 \mathrm{~h} \mathrm{LC50}$ in rainbow trout of 2.7-4.0 $\mathrm{mg} / \mathrm{L}$ [29]. The $48 \mathrm{~h} \mathrm{EC50} \mathrm{for}$ amitraz in gyrodactylids is $0.16 \mu \mathrm{M}(4.6 \mathrm{mg} / \mathrm{L})$, whereas in Daphnia magna Straus, 1820 it has been calculated as $3.4 \mathrm{mg} / \mathrm{L}$ [30]. Although the EC50 values for amitraz are of the same magnitude as the LC50 and EC50 values for trout and Daphnia, it is anticipated that the concentrations required to disrupt the host seeking and attachment behaviour of gyrodactylids will be considerably lower. However, this requires further investigation.

Products containing amitraz were banned in 2010 for pesticidal uses in agriculture due to concerns of human exposure and risks to the environment [31]. Chlordimeform is banned for use as an agricultural pesticide due to concerns that it is carcinogenic to humans and is toxic to aquatic life [32]. Despite these concerns, the compounds can be used to illustrate the presence of key octopaminergic pathways in gyrodactylids.

\section{Conclusions}

This work has made a significant step forward in the observation of gyrodactylid behaviour and is the first time that movements/activity have been studied in detail, suggesting that gyrodactylids are more active in dark than light conditions. Now that the experimental procedures have been developed to observe and record gyrodactylid movements, this system can be used for a wide variety of gyrodactylid behaviour experiments. Further work is required to confirm that gyrodactylid behaviour is affected by light conditions, specifically their behaviours in white light, red light, infrared light and dark conditions. The efficacy experiments have shown that octopaminergic receptors exist in gyrodactylids, as the octopaminergic compounds tested have an effect on gyrodactylids resulting in neuromuscular disturbance and eventually death. The next logical step is to investigate the ability of affected gyrodactylids to reattach to a fish host once they have been exposed to low doses of octopaminergic compounds and whether the effect is permanent or temporary, once they have been removed from the compounds.

These initial results observing gyrodactylid behaviour and the effect of octopaminergic compounds are promising and indicate that there might be potential use of compounds affecting octopamine receptors to control gyrodactylid infections. With the constant threat of $G$. salaris entering UK waterways and the lack of any effective treatment, other than the total eradication of all river fauna using rotenone, it is important that investment is made now to develop new chemical treatments that will specifically target Gyrodactylus infections.

\section{Acknowledgements \\ The authors gratefully acknowledge funding from Defra (project FC1175) to APS. \\ Author details \\ ${ }^{1}$ Institute of Aquaculture, University of Stirling, Stirling FK9 4LA, UK. ${ }^{2}$ Cefas Weymouth Laboratory, The Nothe, Barrack Road, Weymouth, DT4 8UB, UK.}

\section{Authors' contributions}

AJB made significant contributions to the conception and design of the study, constructed experimental equipment, carried out data acquisition, data analysis and interpretation, and drafted the manuscript. MIGM contributed to the design of the study and data acquisition. JEB, SI and ML contributed to the study concept and were involved in critically revising the manuscript. APS supervised the study, contributed to the conception and design of the study, interpretation of results and critically revising the manuscript. All authors read and approved the final manuscript.

\section{Competing interests}

The authors declare that they have no competing interests.

Received: 8 July 2011 Accepted: 27 October 2011

Published: 27 October 2011 


\section{References}

1. Bakke TA, Harris PD, Cable J: Host specificity dynamics: observations on gyrodactylid monogeneans. Int J Parasitol 1992, 32:281-308.

2. Johnsen $\mathrm{BO}, \mathrm{Møk}$ kelgjerd $\mathrm{PI}$, Jensen AJ: The parasite Gyrodactylus salaris on salmon parr in Norwegian rivers, status report at the beginning of year 2000. NINA Oppdrag 1999, 617:1-129.

3. Hansen H, Bachmann L, Bakke TA: Mitochondrial DNA variation of Gyrodactylus spp. (Monogenea, Gyrodactylidae) populations infecting Atlantic salmon, grayling, and rainbow trout in Norway and Sweden. Int J Parasitol 2003, 33:1471-1478.

4. Olstad K, Cable J, Robertsen G, Bakke TA: Unpredicted transmission strategy of Gyrodactylus salaris (Monogenea: Gyrodactylidae): survival and infectivity of parasites on dead hosts. Parasitol 2006, 133:33-41.

5. Branson EJ, Rønsberg SS, Ritchie G: Efficacy of teflubenzuron (Calicide ${ }^{\circledast}$ ) for the treatment of sea lice, Lepeoptheirus salmonis (Krøyer, 1838), infestations of farmed Atlantic salmon (Salmo salar L.). Aquac Res 2000 31:861-867.

6. Malmberg G: The excretory systems and the marginal hooks as a basis for the systematics of Gyrodactylus (Trematoda, Monogenea). Arkiv Zool 1970, 23:1-235.

7. Seuront L, Hwang JS, Tseng LC: Individual variability in the swimming behaviour of the sub-tropical copepod Oncaea venusta (Copepoda: Poecilostomatoida). Mar Ecol Prog Ser 2004, 283:199-217.

8. Uttieri M, Zambianchi E, Strickler JR: Fractal characterization of threedimensional zooplankton swimming trajectories. Ecol Model 2005, 185:51-63.

9. Sigma-Aldrich Chemical Company: Material Safety Data Sheet: Chlordimeform St Louis, USA; 2010.

10. Roeder T: Octopamine in invertebrates. Prog Neurobiol 1999, 59:533-561.

11. Williams CM, Couch MW, Thonoor CM, Midgley JM: Isomeric octopamines: their occurrence and functions. J Pharm Pharmacol 1987, 39:153-157.

12. Cohen DJ, Nathanson JA, Young JG, Shaywitz BA: Clonidine in Tourette's syndrome. Lancet 1979, 314:551-553.

13. Altobelli D, Martire M, Maurizi S, Preziosi P: Interaction of formamidine pesticides with the presynaptic a2-adrenoceptor regulating $\left[{ }^{3} \mathrm{H}\right]$ noradrenaline release from rat hypothalamic synaptosomes. Toxicol Appl Pharm 2001, 172:179-185.

14. Evans PD, Gee JD: Action of formamidine pesticides on octopamine receptors. Nature 1980, 287:60-62.

15. Matsumura F, Beeman RW: Biochemical and physiological effects of chlordimeform. Environ Health Perspec 1976, 14:71-82.

16. Hollingworth R: Chemistry, biological activity and uses of formamidine pesticides. Environ Health Perspec 1976, 14:57-69.

17. Benkó P, Pallos L, Ordögh F, Kiss J: Formamidine derivatives with anthihelminthic activity. Acta Pharm Hung 1968, 38:219-222.

18. Pfeffer M, Dobler G: Tick-borne encephalitis virus in dogs-is this an issue? Parasite Vector 2011, 4:59.

19. Stone BF, Atkinson PW, Knowles CO: Formamidine structure and detachment of the cattle tick Boophilus microplus. Pestic Biochem Phys 1974, 4:407-416.

20. Abbott WS: A method of computing the effectiveness of an insecticide. $J$ Ecol Entomol 1925, 18:265-267.

21. Watson NA, Rohde K: Two new sensory receptors in Gyrodactylus sp. (Platyhelminthes, Monogenea, Monopisthocotylea). Parasitol Res 1994, 80:442-445.

22. Rohde $\mathrm{K}$, Watson N: Paired multiciliate receptor complexes in larval Multicotyle purvisi (Trematoda, Aspidogastrea). Parasitol Res 1990, 76:597-601.

23. Sopott-Ehlers B: Comparative morphology of photoreceptors in free-livng platyhelminths-a survey. Hydrobiologia 1991, 227:231-239.

24. Lyons KM: Sense organs of monogeneans. In Behavioural aspects of parasite transmission. Edited by: Canning EU, Wright CA. London: Academic Press/Linnean Society of London; 1972:181-199.

25. Bakke TA, Jansen PA, Hansen LP: Experimental transmission of Gyrodactylus salaris Malmberg, 1957 (Platyhelminthes, Monogenea) between the Atlantic salmon (Salmo salar) and the European eel (Anguilla anguilla). Can J Zoolog 1991, 69:733-737.

26. Cable J, Scott ECG, Tinsley RC, Harris PD: Behaviour favoring transmission in the viviparous monogenean Gyrodactylus turnbulli. J Parasitol 2002, 88:183-184.
27. Sigma-Aldrich Chemical Company: Material Safety Data Sheet: DLoctopamine hydrochloride St Louis, USA; 2002.

28. Fisher Scientific AB: Material Safety Data Sheet: Clonidine hydrochloride Västra Frölunda, Sweden; 2006.

29. Intervet Australia Pty Ltd: Material Safety Data Sheet: Amitraz Bendigo East, Australia; 2006

30. Sigma-Aldrich Chemical Company: Material Safety Data Sheet: Amitraz St Louis, USA; 2010.

31. Rotterdam Convention on the Prior Informed Consent Procedure for Certain Hazardous Chemicals and Pesticides for International Trade: Technical work: review of notifications of final regulatory action: amitraz Rome 2011.

32. Joint FAO/UNEP Programme for the Operation of Prior Informed Consent: Decision Guidance Documents: Chlordimeform 1991.

doi:10.1186/1756-3305-4-207

Cite this article as: Brooker et al:: The effect of octopaminergic

compounds on the behaviour and transmission of Gyrodactylus.

Parasites \& Vectors 2011 4:207

\section{Submit your next manuscript to BioMed Central and take full advantage of:}

- Convenient online submission

- Thorough peer review

- No space constraints or color figure charges

- Immediate publication on acceptance

- Inclusion in PubMed, CAS, Scopus and Google Scholar

- Research which is freely available for redistribution

Submit your manuscript at www.biomedcentral.com/submit
C) Biomed Central 